\title{
Clinicoepidemiological Features and Mortality Analysis of Deceased Patients with COVID-19 in a Tertiary Care Center
}

Richa Aggarwal ${ }^{1} \odot$, Ridhima Bhatia ${ }^{\odot} \odot$, Kshitija Kulshrestha ${ }^{3} \odot$, Kapil D Soni $^{4} \odot$, Renjith Viswanath ${ }^{5} \odot$, Ashutosh K $\operatorname{Singh}^{6} \odot$, Karthik V lyer ${ }^{7} \odot$, Puneet Khanna ${ }^{8} \odot$, Sulagna Bhattacharjee ${ }^{9} \odot$, Nishant Patel ${ }^{10} \odot$, Ajisha Aravindan ${ }^{11} \odot$, Anju Gupta ${ }^{12} \odot$, Yudhyavir Singh ${ }^{13} \odot$, Venkata Ganesh ${ }^{14} \odot$, Rakesh Kumar ${ }^{15} \odot$, Arshed Ayub $^{16} \odot$, Shailender Kumar ${ }^{17} \odot$, Kellika Prakash ${ }^{18} \odot$, Vineeta Venkateswaran ${ }^{19} \odot$, Debesh Bhoi ${ }^{20} \odot$, Manish Soneja ${ }^{21} \odot$, Purva Mathur ${ }^{22} \odot$, Rajesh Malhotra ${ }^{23} \odot$, Naveet Wig ${ }^{24} \odot$, Randeep Guleria ${ }^{25}$, Anjan Trikha ${ }^{26} \odot$

\begin{abstract}
Background and objective: A large number of studies describing the clinicoepidemiological features of coronavirus disease-2019 (COVID-19) patients are available but very few studies have documented similar features of the deceased. This study was aimed to describe the clinicoepidemiological features and the causes of mortality of COVID-19 deceased patients admitted in a dedicated COVID center in India. Methodology: This was a retrospective study done in adult deceased patients admitted in COVID ICU from April 4 to July 24, 2020. The clinical features, comorbidities, complications, and causes of mortality in these patients were analyzed. Pediatric deceased were analyzed separately. Results: A total of 654 adult patients were admitted in the ICU during the study period and ICU mortality was 37.7\% (247/654). Among the adult deceased, $65.9 \%$ were males with a median age of 56 years [interquartile range (IQR), 41.5-65] and $94.74 \%$ had one or more comorbidities, most common being hypertension (43.3\%), diabetes mellitus (34.8\%), and chronic kidney disease (20.6\%). The most common presenting features in these deceased were fever (75.7\%), cough (68.8\%), and shortness of breath (67.6\%). The mean initial sequential organ failure assessment score was $9.3 \pm 4.7$ and $24.2 \%$ were already intubated at the time of admission. The median duration of hospital stay was 6 days (IQR, 3-11). The most common cause of death was sepsis with multi-organ failure (55.1\%) followed by severe acute respiratory distress syndrome (ARDS) (25.5\%). All pediatric deceased had comorbid conditions and the most common cause of death in this group was severe ARDS.

Conclusion: In this cohort of adult deceased, most were young males with age less than 65 years with one or more comorbidities, hypertension being the most common. Only $5 \%$ of the deceased had no comorbidities. Sepsis with multi-organ dysfunction syndrome was the most common cause of death.
\end{abstract}

Keywords: Clinicoepidemiological features, Comorbidities, COVID-19 deceased, ICU, Mortality analysis, Multi-organ dysfunction syndrome. Indian Journal of Critical Care Medicine (2021): 10.5005/jp-journals-10071-23848

\section{INTRODUCTION}

Coronavirus disease-2019 (COVID-19) emerged in China in December 2019 and engulfed the whole world in a very short period of time. Worldwide till now around 95 million patients have been infected and there have been more than 2 million deaths. India is also severely affected. It has infected more than 10 million people in India and has led to more than 1.5 lakh deaths till now. ${ }^{1}$

The clinical spectrum of COVID-19 is varied, ranging from asymptomatic carriers to severe pneumonia, acute respiratory distress syndrome (ARDS) profiles, multi-organ involvement, and death. ${ }^{2}$ Nearly $14-15 \%$ of patients develop severe disease and $5 \%$ become critically ill. ${ }^{3}$ Earlier thought to be primarily affecting the pulmonary system, a number of symptoms related to other organ systems have been widely recognized as initial presenting features of COVID-19 infection. ${ }^{4,5}$ These extrapulmonary manifestations can lead to complications and increase morbidity. The prevalence of mortality among hospitalized patients with COVID-19 disease varies from 6.3 to $26.85 \%$ in different parts of the world. ${ }^{6}$ Various studies have looked into and analyzed the risk factors for severe disease and predictors of mortality. ${ }^{7,8}$ However, studies regarding the clinicoepidemiological features of the deceased and causes of mortality are sparse. Some studies of COVID-19 related mortalities from US, China, Italy, and Spain are available $;^{9-17}$ however, such
1,3 Critical and Intensive Care, JPN Apex Trauma Centre, AlIMS, New Delhi, India

2,5-20,26 Department of Anaesthesiology, Pain Medicine and Critical Care, AlIMS, New Delhi, India

${ }^{21,24}$ Department of Medicine, AllMS, New Delhi, India

${ }^{22}$ Department of Laboratory Medicine, AlIMS, New Delhi, India

${ }^{23}$ Department of Orthopaedics, AlIMS, New Delhi, India

${ }^{25}$ Department of Pulmonary and Sleep Medicine, AlIMS, New Delhi, India

Corresponding Author: Richa Aggarwal, Critical and Intensive Care, JPN Apex Trauma Centre, AlIMS, New Delhi, India, Phone: +91 9873731042, e-mail: pathakricha@yahoo.co.in

How to cite this article: Aggarwal R, Bhatia R, Kulshrestha K, Soni $K D$, Viswanath R, Singh AK, et al. Clinicoepidemiological Features and Mortality Analysis of Deceased Patients with COVID-19 in a Tertiary Care Center. Indian J Crit Care Med 2021; 25(6):622-628.

Source of support: Nil

Conflict of interest: None

descriptive study has not been done from Indian subcontinent so far. This study was aimed to describe the clinicoepidemiological features and the causes of mortality of COVID-19 deceased patients

(c) Jaypee Brothers Medical Publishers. 2021 Open Access This article is distributed under the terms of the Creative Commons Attribution 4.0 International License (https://creativecommons.org/licenses/by-nc/4.0/), which permits unrestricted use, distribution, and non-commercial reproduction in any medium, provided you give appropriate credit to the original author(s) and the source, provide a link to the Creative Commons license, and indicate if changes were made. The Creative Commons Public Domain Dedication waiver (http://creativecommons.org/publicdomain/zero/1.0/) applies to the data made available in this article, unless otherwise stated. 
admitted in our hospital during the initial period of the pandemic spread in the country from April to July.

\section{Materials and Methods}

This was a retrospective study conducted in the COVID center of AlIMS, New Delhi, after approval from the institutional ethics committee. This study analyzed data of patients who died in the course of treatment in the ICU of COVID-19 center during the study period between April 4 and July 24, 2020. All the patients admitted to the center were moderate to severe confirmed COVID-19 patients whose real-time reverse-transcription polymerase chain reaction assay findings for nasal or pharyngeal swab specimens were positive. Mild cases were admitted in different centers. Criteria for ICU admission were patients with severe disease i.e., tachypnea with respiratory rate greater than $30 /$ minute or $\mathrm{SpO}_{2}$ less than $90 \%$ on room air, patient with hemodynamic instability, encephalopathy or patients with moderate disease who had risk factors for severe disease.

\section{Data Collection}

Data related to demography and clinical course of all the patients who died in the ICU during the study period was collected from their electronic medical records, patients' daily progress charts, and nursing notes. Patients' age, sex, comorbidities, complaints at the time of presentation, complications during treatment, duration of hospital stay, and cause of death were noted and analyzed. Data regarding adult and pediatric deceased were analyzed separately. Adult patients were further divided into age-groups of 18 to 50 , 51 to 65 , and more than 65 years and their clinical characteristics and outcomes were compared.

\section{Statistical Analysis}

The data were summarized and analyzed using STATA (Version 14.0) software and expressed as mean \pm SD/Median (min, max) and numbers and percentages as appropriate to describe the patient's demographic and clinical characteristics. Wilcoxon-Ranksum test was used to compare the non-normal quantitative values while chi-square/Fisher's exact test was applied for association between categorical variables and for comparison between stratified agegroups. Kruskal-Wallis was used to see the difference in age-groups for the days of stay followed by multiple comparison tests between the groups. A value of $p$ less than 0.05 was considered as statistically significant in the study.

\section{Results}

During the study period, a total of 1,420 patients (adult and pediatric) were admitted in the center. The deaths of adults and pediatric age-groups were analyzed separately.

\section{Adult Fatalities}

There were 654 adult admissions in the ICU during the study period out of which 247 died. The ICU mortality for adults was $37.7 \%$ (247/654).

Among the adult patients who did not survive, the youngest was 18 years old and the eldest was 97 years old. The median age was 56 years [interquartile range (IQR), 41.5-65] and most of them were males (65.9\%). Age distribution of adults in various age-groups is given in Table 1.

Most of the adult patients who died (94.74\%) had 1 or more comorbidities. Preexisting hypertension was the most frequently seen comorbidity in 107 (43.32\%) patients followed by diabetes mellitus in 86 (34.82\%) patients and chronic kidney disease in $51(20.6 \%)$ patients. Other comorbidities are tabulated in Table 1. Among the patients with comorbidities, $39 \%$ of patients had one comorbidity, $27.5 \%$ had two comorbidities, $21 \%$ had three, and $6 \%$ had more than three comorbidities. The frequency of patients with different numbers of comorbidities is depicted in Figure 1.

Twenty-nine patients had some kind of malignancy, out of which 14 suffered from hematological malignancies and remaining 15 had solid organ tumors. Besides these, other infrequently encountered comorbidities were postrenal transplant, cardiomyopathy, cholelithiasis, complete heart block with pacemaker in situ, HIV

Table 1: Clinical characteristics of study patients

\begin{tabular}{lc}
\hline Characteristics & Patients \\
\hline Age median (IQR) (years) & $56(41.5-65)$ \\
Age distribution (years) & No. (\%) \\
$18-50$ & $104 / 247(42.1)$ \\
$51-65$ & $86 / 247(34.8)$ \\
More than 65 & $57 / 247(23.1)$ \\
Male sex (\%) & $163 / 247(65.9)$ \\
Comorbidities & No. of patients (\%) \\
Hypertension & $107(43.3)$ \\
Diabetes mellitus & $86(34.8)$ \\
Chronic kidney disease & $51(20.6)$ \\
Coronary artery disease & $40(16.2)$ \\
Malignancy & $29(11.7)$ \\
Cerebrovascular event & $29(11.7)$ \\
Tuberculosis & $21(8.5)$ \\
Chronic liver disease & $19(7.7)$ \\
Hypothyroidism & $13(5.3)$ \\
Chronic obstructive airway disease & $11(4.5)$ \\
Trauma & $7(2.8)$ \\
Rheumatic heart disease & $5(2.0)$ \\
Others & $55(22.3)$ \\
\hline
\end{tabular}

IQR, interquartile range

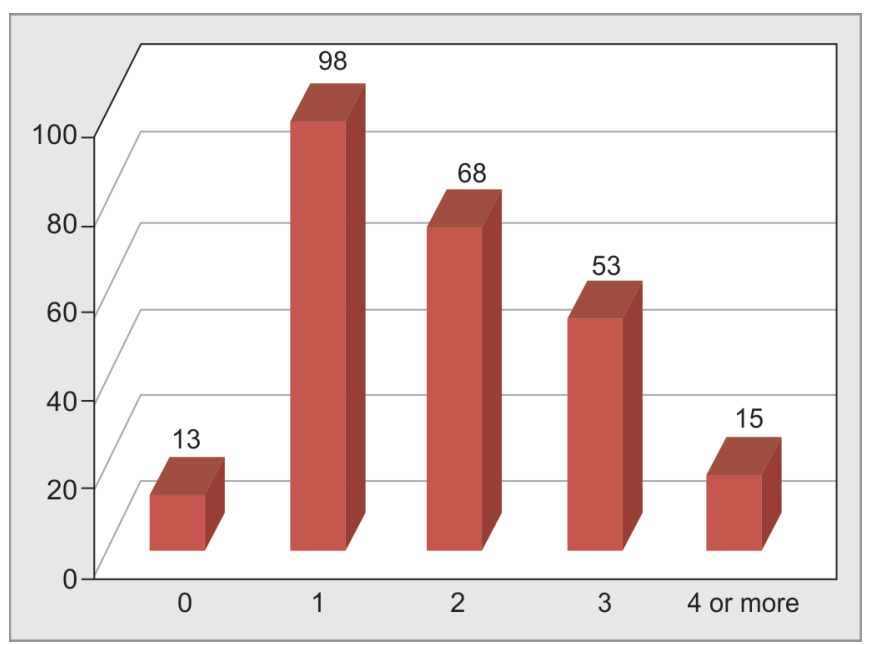

Fig. 1: Frequency of patients with different number of comorbidities 
ulcerative colitis, sarcoidosis, interstitial lung disease, liver abscess, aspergilloma, shoulder abscess, peripheral vascular disease, parkinsonism, corrosive ingestion, mesenteric ischemia, dementia, depression, aplastic anemia, cervical spondylosis, systemic sclerosis, ulnar, and subclavian artery thrombosis.

The most common presenting symptom among deceased was fever $(75.7 \%)$ followed by cough $(68.8 \%)$, shortness of breath (67.6\%), and altered sensorium (19.8\%) as shown in Table 2. Besides these, other patients presented with chest pain, abdominal pain or distension, generalized weakness, diarrhea, and headache. Approximately $20 \%$ of patients presented with nonspecific complaints including myalgia, decreased urine output, jaundice, upper limb pain, generalized edema, epistaxis, and joint pain.

The patients had varying degrees of severity of illness. The initial sequential organ failure assessment (SOFA) score was calculated for 232 deceased, the data were missing for 15 patients. The mean SOFA score was 9.3 with a standard deviation of 4.07. The initial SOFA score was significantly higher in males as compared to females ( $p=0.03$ ). Out of 247 deceased, 60 patients were received intubated in our center from the screening area. Patients were given treatment according to the institutional protocol. The patients were initially managed on oxygen by facemask and then as the oxygen requirement increased, they were managed on high flow nasal cannula (HFNC) and noninvasive ventilation (NIV) before invasive ventilation as per SCCM guidelines. Seventy-five patients were intubated in the first 24 hours of admission. The number of patients who received HFNC and NIV are mentioned in Table 3. As the disease advanced, many patients developed multisystem involvement. However, the predominant system involved due to COVID was the respiratory system in $66 \%$ of the patients followed by the neurological system and cardiovascular system. One twenty one patients developed acute kidney injury (AKI) and 39 received RRT (Table 3). Repeat SOFA score was calculated on day 4 of admission after 72 hours. Repeat SOFA was available for 133 patients as 99 patients died within 3 days of admission to ICU.

\section{Duration of Stay and Cause of Death}

Among the deceased adults, the median duration of hospital stay was 6 days (IQR, 3-11) with maximum stay of 37 days and minimum of 1 day.

The cause of death was analyzed in all the deceased (Table 4). Sepsis with multi-organ dysfunction remained the leading cause of death ( $55.1 \%$ ) followed by severe ARDS ( $25.5 \%)$, cardiogenic shock, intracranial hypertension, and suspected pulmonary embolism.

There were 41 patients who died within 24 hours of admission. Among these, $90.24 \%$ of them reported a history of one or more

Table 2: Distribution of presenting complaints

\begin{tabular}{lc}
\hline Presenting complaints & No. (\%) \\
\hline Fever & $187(75.7)$ \\
Cough & $170(68.8)$ \\
Shortness of breath & $167(67.6)$ \\
Altered sensorium & $49(19.8)$ \\
Chest pain & $13(5.3)$ \\
Abdominal pain/distension & $12(4.9)$ \\
Weakness & $6(2.4)$ \\
Diarrhea & $6(2.4)$ \\
Headache & $4(1.6)$ \\
Others & $50(20.2)$ \\
\hline
\end{tabular}

comorbidities and majority had respiratory distress at presentation. Most of them were shifted intubated to our center. Four patients received cardiopulmonary resuscitation in the emergency room and were postarrest patients. The cause of death of these patients is depicted in Figure 2.

Table 3: SOFA scoring, modes of oxygen therapy given, and renal complications in deceased

\begin{tabular}{lc}
\hline ICU parameters & $\begin{array}{c}\text { Mean (SD) or No. of } \\
\text { Patients (\%) }\end{array}$ \\
\hline Initial SOFA (232 patients) & $9.3(4.07)$ \\
SOFA at 72 hrs (133 patients) & $10.2(3.9)$ \\
Patients received intubated & $60(24.2)$ \\
Patients intubated within first 24 hrs & $75(30.3)$ \\
Patients received HFNC & $112(45.3)$ \\
Patients received NIV & $45(18.2)$ \\
Patients developed AKI & $121(48.9)$ \\
Patients received RRT & $39(15.8)$ \\
\hline
\end{tabular}

SOFA, sequential organ failure assessment; HFNC, high-flow nasal cannula; NIV, noninvasive ventilation; AKI, acute kidney injury; RRT, renal replacement therapy

Table 4: Cause of death

\begin{tabular}{lll}
\hline SI. & & \\
No. & Cause of death & Frequency (\% of patients) \\
\hline 1 & Sepsis with multi organ dysfunction & $136(55.1)$ \\
2 & Severe ARDS & $63(25.5)$ \\
3 & Cardiogenic shock & $23(9.3)$ \\
4 & Stroke/cerebral bleed & $17(6.9)$ \\
5 & Pulmonary embolism & $7(2.8)$ \\
6 & Hemorrhage & $1(0.40)$ \\
\hline
\end{tabular}

MODS, multi-organ dysfunction syndrome; ARDS, acute respiratory distress syndrome

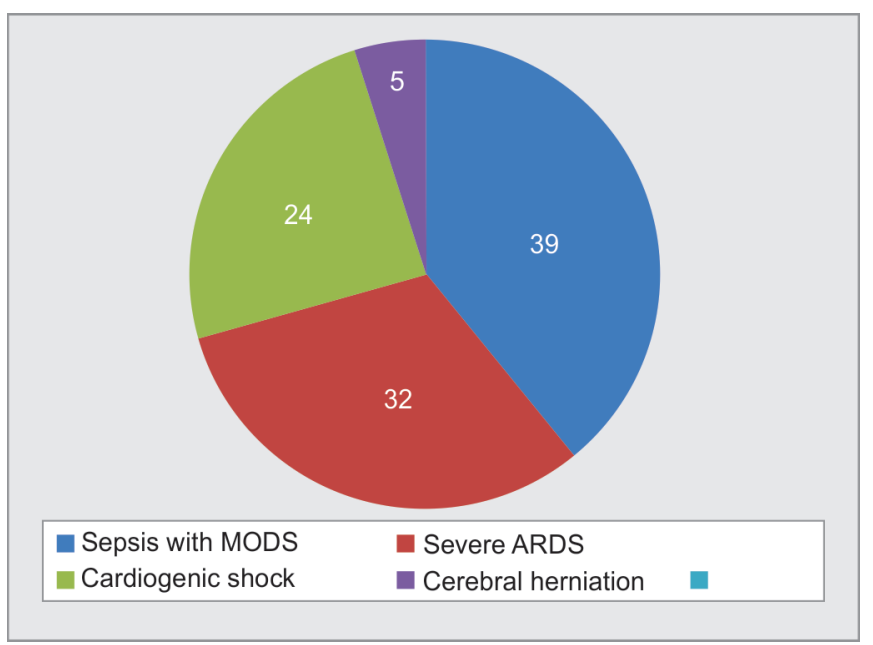

Fig. 2: Cause of death in patients who died within 24 hours of admission to COVID-19 center. MODS, multi-organ dysfunction; ARDS, acute respiratory distress syndrome 


\section{Age-related Analysis}

The study patients were stratified into three age-groups (18-50, $51-65$, and $>65$ years) to find out age-related differences in the number of comorbidities, presenting symptoms, duration of illness, and cause of death (Table 5).

In the study cohort, $42.1 \%$ of the deceased were in age-group between 18 years and 50 years, 34.8\% in age-group $51-65$ years, and $23.1 \%$ in the group above the age of 65 years. There was no difference in the male-to-female ratio between the three groups. The percentage of deceased having multiple comorbidities (two or more) was significantly higher in the age-group above 65 years as compared to younger age-groups. Multiple comorbidities were seen in $68.4 \%$ of patients above the age of 65 years, as compared to $59.3 \%$ in age-group $51-65$ years and $44.2 \%$ in patients in 18-50 years of age.

The most frequent presenting complaints were similar in deceased of all age-groups with no significant difference. Initial SOFA score and percentage of patients given HFNC and NIV, and patients developing AKI were also similar in all the three groups. However, the duration of stay in the hospital was higher in the elderly deceased population. The percentage mortality was significantly higher in the age-group of more than 65 years as compared to other groups. The percentage mortality in different age-groups was $30.2 \%$ in age-group between 18 and 50 years, $43.2 \%$ in age-group between 51 years and 65 years, and $51.3 \%$ in age-group more than 65 years.

\section{Pediatric Fatalities}

There were 46 pediatric admissions during the study period and six COVID-19 related deaths, the ICU mortality among the pediatric age-group being $13 \%$ (6/46). The age-group of the deceased varied from 6 months to 16 years as depicted in Table 6 . All of these patients had comorbidities including congenital heart disease, tubercular meningitis, endocrine disorders, and hematologic malignancies. Mean hospital duration of stay was 4.33 days. Most common cause of death was ARDS followed by sepsis with multi-organ dysfunction.

Table 5: Characteristics of the patients according to different age-groups

\begin{tabular}{|c|c|c|c|c|}
\hline \multirow[t]{3}{*}{ Total admissions in COVID-19 center } & \multicolumn{3}{|c|}{ Age-group (years) } & \multirow[t]{2}{*}{$p$ value } \\
\hline & \multicolumn{3}{|c|}{ Age-group (years) } & \\
\hline & $18-50 n(\%)$ & $51-65 n(\%)$ & $>65 n(\%)$ & $p$ value \\
\hline ICU admissions (\% of total ICU admissions) & $344(48.6)$ & $199(28.1)$ & $111(15.7)$ & $<0.001$ \\
\hline ICU mortality (\%) & $104(30.2)$ & $86(43.2)$ & $57(51.3)$ & $<0.001$ \\
\hline Sex (male:female) & $65: 39$ & $57: 29$ & $41: 16$ & 0.48 \\
\hline \multicolumn{5}{|l|}{ Number of comorbidities (\% of patients) } \\
\hline 0 & $9(8.6)$ & $3(3.5)$ & $1(1.7)$ & \\
\hline 1 & $49(47.1)$ & $32(37.2)$ & $17(29.8)$ & \\
\hline$\geq 2$ & $46(44.2)$ & $51(59.3)$ & $39(68.4)$ & 0.024 \\
\hline \multicolumn{5}{|l|}{ Presenting complaints ( $\%$ of patients) } \\
\hline Fever & $77(74.0)$ & $65(75.6)$ & 45 (78.9) & 0.78 \\
\hline Cough & $71(68.3)$ & $56(65.1)$ & $43(75.4)$ & 0.42 \\
\hline Breathlessness & $67(64.4)$ & $58(67.4)$ & $42(73.7)$ & 0.48 \\
\hline Altered sensorium & $21(20.2)$ & $15(17.4)$ & $13(22.8)$ & 0.72 \\
\hline Abdominal pain/distension & $6(5.8)$ & $6(6.9)$ & $0(0)$ & 0.11 \\
\hline Chest pain & $3(2.9)$ & $8(9.3)$ & $2(3.5)$ & 0.14 \\
\hline Nonspecific symptoms & $28(26.9)$ & $16(18.6)$ & $6(10.5)$ & 0.04 \\
\hline Initial SOFA mean (SD) & $9.8(3.9)$ & $9.2(4.1)$ & $8.4(3.9)$ & 0.86 \\
\hline Patients ventilated within first $24 \mathrm{hrs}$ including patients received intubated & $57(54.8)$ & $51(59.3)$ & $27(47.3)$ & 0.37 \\
\hline Patients given HFNC & $47(45.1)$ & $35(40.7)$ & $30(52.6)$ & 0.37 \\
\hline Patients given NIV & $21(20.1)$ & $11(12.7)$ & $13(22.8)$ & 0.24 \\
\hline Patients developing AKI & $51(49.0)$ & $45(52.3)$ & $25(43.8)$ & 0.61 \\
\hline Patients received RRT & $20(19.2)$ & $12(13.9)$ & $7(12.2)$ & 0.43 \\
\hline Median days of illness (IQR) & $5(2-8)$ & $5(3-11)$ & $9(5-13)$ & 0.001 \\
\hline \multicolumn{5}{|l|}{ Cause of death } \\
\hline Sepsis with MODS & $50(48.1)$ & $49(56.9)$ & $37(64.9)$ & \\
\hline ARDS & $28(26.9)$ & $22(25.6)$ & $13(22.8)$ & \\
\hline Cardiogenic shock & $8(7.7)$ & $9(10.5)$ & $6(10.5)$ & \\
\hline Stroke, CNS bleed & $13(12.5)$ & $4(4.6)$ & $0(0)$ & \\
\hline Pulmonary embolism & $4(3.8)$ & $2(2.3)$ & $1(1.7)$ & \\
\hline Hemorrhage & $1(0.9)$ & $0(0)$ & $0(0)$ & 0.115 \\
\hline
\end{tabular}

SOFA, sequential organ failure assessment; HFNC, high flow nasal cannula; NIV, noninvasive ventilation; AKI, acute kidney injury; RRT, renal replacement therapy 
Table 6: Pediatric patients

\begin{tabular}{llllll}
\hline SI. & Age (years)/ & & $\begin{array}{l}\text { Length of stay } \\
\text { in hospital }\end{array}$ & Comorbidities & Cause of death \\
\hline 1 & No.5/M & Fever & 2 & Cyanotic congenital heart disease & ARDS \\
2 & $3 / \mathrm{M}$ & Fever, shortness of breath & 7 & ALL with CNS metastasis & Sepsis \\
3 & $13 / \mathrm{M}$ & Fever, vomiting, hematemesis & 1 & Aplastic anemia & ARDS \\
4 & $12 / \mathrm{M}$ & Shortness of breath & 7 & DM, Hypothyroid, nephrotic syndrome & ARDS \\
5 & $15 / \mathrm{M}$ & Fever, altered sensorium & 1 & TB meningitis with hydrocephalus & Cerebral herniation \\
6 & $16 / \mathrm{F}$ & Fever, cough & 8 & AML with fungal pneumonia & Acute pulmonary hemorrhage \\
\hline
\end{tabular}

MODS, multi-organ dysfunction syndrome; ARDS, acute respiratory distress syndrome; ALL, acute lymphoblastic leukemia; AML, acute myeloid leukemia; CNS, central nervous system; DM, diabetes mellitus; TB, tuberculosis

\section{Discussion}

This study retrospectively analyzed clinicoepidemiological characteristics, course of the disease, and cause of mortality of COVID-19 patients who died in the ICU. Total of 1,420 confirmed COVID-19 patients of all ages were admitted in the COVID center in the study period. Almost half (49.3\%) of the hospitalized patients received ICU care during the course of illness. This figure varies from 5 to $46.8 \%$ of hospitalized patients in different studies ${ }^{9-11}$ and is related to the availability of ICU resources in that region.

The ICU mortality of COVID-19 patients varies from 8.0 to $66.7 \%$ in different studies. ${ }^{18}$ In our center, the hospital mortality was $18.2 \%$ and ICU mortality was $36.1 \%$. Similar mortality rates have been reported in other studies from US, Spain, Italy, and few studies from China. ${ }^{9,10,16}$ However, there are other studies from China $^{2}$ which depict lower overall mortality rates. As the pandemic is evolving and our understanding of the disease is increasing, there has been a steady decline in the mortality rate. ${ }^{19}$

Approximately $60 \%$ of all admitted patients were males in our center. An almost alike proportion of male patients has been documented in all other studies suggesting male predisposition for this disease across various ethnic and racial groups. ${ }^{9,10,15}$ Similarly, among the deceased adults, $66 \%$ were males and among pediatric fatalities, all were males except one.

In our study population of adult deceased, $42.1 \%$ were of age-group of $18-50$ years, $35 \%$ in the age-group $51-64$ years, and only about $23 \%$ were above 65 years age-group. This was a deviation from the studies from other parts of the world where most of the nonsurvivors were from a much older age-group ${ }^{10,15,20}$ and could be explained by the majority of the young population in India, the percentage of the elderly population ( $>60$ years) being $6.8 \% .{ }^{21}$ In our study, $95 \%$ of the adults deceased and all of the pediatric ones had at least one comorbid condition. Mortality studies from Spain and Italy ${ }^{10,15}$ have reported a similar incidence of comorbidities in nonsurvivors. However, few other studies ${ }^{11,16}$ report lesser incidence of comorbidities than ours. In our cohort, hypertension was the most common comorbidity seen followed by DM and CKD. Similarly, worldwide studies have shown hypertension followed by diabetes mellitus and cardiovascular comorbid conditions to be associated with the highest mortality. ${ }^{12,14,22}$ Role of ACE-2 receptor in entry of SARSCoV-2 virus into a host cell is one of the proposed reasons for the highest incidence of COVID-19 in hypertensive patients. ${ }^{23}$

In the present study, the elderly (>65 years old) deceased had more comorbidities than younger deceased suggesting that elderly population with higher number of comorbidities are more susceptible to adverse outcomes following COVID-19 infection, while factors other than number of comorbidities could be a significant variable in younger population. ${ }^{15}$ Malignancy was seen in $11.74 \%$ of patients in our study which was higher than other reported incidences. ${ }^{12,13,16}$

The most common presenting complaints in our deceased population were fever, cough, and breathlessness similar to the findings of earlier studies. ${ }^{3,24}$ Few patients initially presented for unrelated diagnoses and then later tested positive for COVID-19. Nonspecific symptoms were significantly more common in younger deceased.

The median initial SOFA score was 9.3 in our study. This was higher as compared to studies from US and China ${ }^{11,25,26}$ reflecting increased severity of COVID-19 at ICU admission in our cohort. High SOFA scores at ICU admission or their progression over 48 hours have been associated with poor outcome of COVID-19. ${ }^{25,27}$ Around $24 \%$ of our deceased were received intubated from the screening area and another $30 \%$ got intubated within the first 24 hours. HFNC was used in $45 \%$ of deceased in our study similar to studies from China where HFNC use among nonsurvivors was 21.1 to $41 \%$. $^{11,14}$ Only $18.2 \%$ of patients received NIV in our cohort and even in the published literature, proportion of nonsurvivors receiving noninvasive ventilatory support has been variable. ${ }^{11,14,17}$ Use of NIV was greater in elderly subgroup of nonsurvivors in other studies ${ }^{16}$ unlike our study.

The median duration of ICU stay among deceased was 6 days in our study. There was significant variation in median duration of ICU stay reported in other studies ranging from 6 days to 11.5 days. ${ }^{12,16}$ Elderly deceased (>65 years) had significantly longer average duration of hospital stay of 9 days while younger had average 5 days of stay. However, a study in China on deceased patients ${ }^{28}$ reported a longer average duration of hospital stay in younger patients. The reason for shorter stay in the younger age-group could be either the patients presented to the hospital late in the disease process or had severe cytokine storm-related multi-organ failure. Ours being a tertiary care center, patients were shifted after deterioration from other hospitals. The incidence of AKI in our study was 48.9 and $15.8 \%$ received RRT similar to the study by Ahmed et al. in which AKI incidence was around 10 to $50 \%$ in critically ill nonsurvivors and around $10-18.5 \%$ received RRT. ${ }^{29}$

Forty-one patients died within 24 hours of admission to ICU. These patients either had severe illness, coexisting decompensated comorbid illness, or were referred from other hospitals. Some were postarrest patients who collapsed in the emergency room, received $\mathrm{CPR}$, and were revived. These patients were more likely to have a poor prognosis and shorter clinical course in the hospital.

Sepsis with multi-organ dysfunction syndrome (MODS) was the most common cause of death in our adult patients followed by severe ARDS and cardiogenic shock. Earlier studies ${ }^{11,24}$ have 
also described multi-organ failure as the most common cause of death in the Chinese population while many other studies reported respiratory failure as the leading cause of death. ${ }^{12,13,30}$ The reduced incidence of respiratory failure among the deceased in our study can be explained on the basis that $95 \%$ of our study cohort had one or more comorbidities that already compromised other organs. Moreover, all our severely affected patients were given ICU admissions as there were enough ICU beds available and we were able to give rescue therapies like prone ventilation for severe ARDS patients. Our scenario was different from other studies where many patients were not able to get supportive treatment as the number of patients requiring ICU care overwhelmed their medical system. Other rare causes of death were raised intracranial pressure and suspected pulmonary embolism.

Of all the admitted patients, COVID-19 related mortality was much lower (5.6\%) in pediatric age-group compared to adults (18.8\%). This correlated with the acknowledged low pediatric mortality rates by other authors. ${ }^{31-33}$ In pediatric patients, respiratory failure secondary to ARDS was the most common cause of death. Only a few cases of pediatric COVID-19 mortality have been reported in the literature, wherein comorbidities and multi-organ dysfunction are the most common cause. ${ }^{33}$

\section{Limitations}

Ours was a retrospective study done in patients who died in ICU. As only data related to the deceased was studied, it is not possible for us to comment on risk factors for more severe infection or death due to COVID-19. Only deaths till July 24 were included in the study. Patients admitted to the hospital during the study duration could have died later during the illness, which has not been included.

\section{Conclusion}

In this single-center retrospective study of the deceased, $65.9 \%$ of the deceased were males. Most of them (76.8\%) were of the age less than 65 years indicative of the majority of young population of India. Nearly all patients had single or multiple comorbidities, most common being hypertension followed by diabetes mellitus and chronic kidney disease. The most common cause was of death was sepsis with MODS followed by ARDS. There were a significant number of patients (16.6\%) who presented late in the disease process and died within 24 hours.

\section{Acknowledgment}

We acknowledge Dr. Maroof Khan for statistical analysis of the data for this study.

\section{OrCID}

Richa Aggarwal ㄴ) https://orcid.org/0000-0002-4531-2759 Ridhima Bhatia (ㄴ) https://orcid.org/0000-0002-0084-1948 Kshitija Kulshrestha (1) https://orcid.org/0000-0002-9652-142X Kapil D Soni @ https://orcid.org/0000-0003-1214-4119 Renjith Viswanath ㄴ) https://orcid.org/0000-0003-4198-4256 Ashutosh K Singh (1) https://orcid.org/0000-0002-4421-8090 Karthik V lyer @ https://orcid.org/0000-0002-0832-7433 Puneet Khanna (1) https://orcid.org/0000-0002-9243-9963 Sulagna Bhattacharjee (ㄴ) https://orcid.org/0000-0001-8671-6875 Nishant Patel @ https://orcid.org/0000-0001-9376-4963 Ajisha Aravindan (1) https://orcid.org/0000-0003-1071-8596 Anju Gupta 나 https://orcid.org/0000-0003-1726-1488
Yudhyavir Singh @ https://orcid.org/0000-0002-5101-7609 Venkata Ganesh @ 1 https://orcid.org/0000-0001-8265-5198 Rakesh Kumar @ https://orcid.org/0000-0002-1539-8264 Arshed Ayub (1) https://orcid.org/0000-0002-8441-2509 Shailender Kumar (ㄷ) https://orcid.org/0000-0003-1140-5444 Kellika Prakash (1) https://orcid.org/0000-0002-2022-3100 Vineeta Venkateswaran (1) https://orcid.org/0000-0003-2234-8035

Debesh Bhoi $\odot$ https://orcid.org/0000-0003-2047-3115

Manish Soneja @ https://orcid.org/0000-0002-8619-7929

Purva Mathur (1) https://orcid.org/0000-0003-4429-3688

Rajesh Malhotra @ https://orcid.org/0000-0001-5971-003X

Naveet Wig $\odot$ https://orcid.org/0000-0002-6603-601X

Randeep Guleria () https://orcid.org/0000-0002-4213-0052

Anjan Trikha 10 https://orcid.org/0000-0002-6001-8486

\section{References}

1. Worldometer info. World/Countries/India; 2020. Available from: https://www.worldometers.info/coronavirus/country/india [Accessed on January 17, 2020].

2. Bal A, Agrawal R, Vaideeswar P, Arava S, Jain A. COVID-19: an up-todate review - from morphology to pathogenesis. Indian J Pathol Microbiol 2020;63(3):358-366. DOI: 10.4103/IJPM.IJPM_779_20.

3. Wu Z, McGoogan JM. Characteristics of and important lessons from the coronavirus disease 2019 (COVID-19) outbreak in China: summary of a report of 72314 cases from the Chinese Center for Disease Control and Prevention. JAMA 2020;323(13):1239-1242. DOI: 10.1001/ jama.2020.2648.

4. Behzad S, Aghaghazvini L, Radmard AR, Gholamrezanezhad A. Extrapulmonary manifestations of COVID-19: radiologic and clinical overview. Clin Imaging 2020;66:35-41. DOI: 10.1016/j. clinimag.2020.05.013.

5. Zheng KI, Feng G, Liu WY, Targher G, Byrne CD, Zheng MH. Extrapulmonary complications of COVID-19: a multisystem disease? J Med Virol 2020;10.1002/jmv.26294. DOI: 10.1002/ jmv.26294.

6. Noor FM, Islam MM. Prevalence and associated risk factors of mortality among COVID-19 patients: a meta-analysis. J Community Health 2020;45(6):1270-1282. DOI: 10.1007/s10900-020-00920-x.

7. Gupta S, Hayek SS, Wang W, Chan L, Mathews KS, Melamed ML, et al. Factors associated with death in critically ill patients with coronavirus disease 2019 in the US. JAMA Intern Med 2020;180(11):1-12. DOI: 10.1001/jamainternmed.2020.3596.

8. Grasselli G, Greco M, Zanella A, Albano G, Antonelli M, Bellani G. Risk factors associated with mortality among patients with COVID-19 in intensive care units in Lombardy, Italy. JAMA Intern Med 2020;180(10):1345-1355. DOI: 10.1001/jamainternmed.2020.3539.

9. Cummings MJ, Baldwin MR, Abrams D, Jacobson SD, Meyer BJ, Balough EM, et al. Epidemiology, clinical course, and outcomes of critically ill adults with COVID-19 in New York City: a prospective cohort study. Lancet 2020;395(10239):1763-1770. DOI: 10.1016/S01406736(20)31189-2.

10. Rivera-Izquierdo $M$, Del Carmen Valero-Ubierna M, R-delAmo JL, Fernández-García MÁ, Martínez-Diz S, Tahery-Mahmoud A, et al. Sociodemographic, clinical and laboratory factors on admission associated with COVID-19 mortality in hospitalized patients: a retrospective observational study. PLoS One 2020;15(6):e0235107. DOI: 10.1371/journal.pone.0235107.

11. Du RH, Liu LM, Yin W, Wang W, Guan LL, Yuan ML, et al. Hospitalization and critical care of 109 decedents with COVID-19 pneumonia in Wuhan, China. Ann Am Thorac Soc 2020;17(7):839-846. DOI: 10.1513/ AnnalsATS.202003-2250C.

12. Du Y, Tu L, Zhu P, Mu M, Wang R, Yang P, et al. Clinical features of 85 fatal cases of COVID-19 from Wuhan. A retrospective observational study. Am J Respir Crit Care Med 2020;201(11):1372-1379. DOI: 10.1164/ rccm.202003-05430C. 
13. Yang F, Shi S, Zhu J, Shi J, Dai K, Chen X. Analysis of 92 deceased patients with COVID-19. J Med Virol 2020;92(11):2511-2515. DOI: 10.1002/jmv.25891.

14. Wang Y, Lu X, Li Y, Chen H, Chen T, Su N, et al. Clinical course and outcomes of 344 intensive care patients with COVID-19. Am J Respir Crit Care Med 2020;201(11):1430-1434. DOI: 10.1164/rccm.2020030736LE.

15. Palmieri L, Vanacore N, Donfrancesco C, Lo Noce C, Canevelli M, Punzo $\mathrm{O}$, et al. Clinical characteristics of hospitalized individuals dying with COVID-19 by age group in Italy. J Gerontol A Biol Sci Med Sci 2020;75(9):1796-1800. DOI: 10.1093/gerona/glaa146.

16. Biagi A, Rossi L, Malagoli A, Zanni A, Sticozzi C, Comastri G, et al. Clinical and epidemiological characteristics of 320 deceased patients with COVID-19 in an Italian Province: a retrospective observational study. J Med Virol 2020;92(11):2718-2724. DOI: 10.1002/jmv.26147.

17. Grasselli G, Zangrillo A, Zanella A, Antonelli M, Cabrini L, Castelli A, et al. Baseline characteristics and outcomes of 1591 patients infected with SARS-CoV-2 admitted to ICUs of the Lombardy Region, Italy. JAMA 2020;323(16):1574-1581. DOI: 10.1001/jama.2020.5394.

18. Quah P, Li A, Phua J. Mortality rates of patients with COVID-19 in the intensive care unit: a systematic review of the emerging literature. Crit Care 2020;24(1):285. DOI: 10.1186/s13054-020-03006-1.

19. Rajgor DD, Lee MH, Archuleta S, Bagdasarian N, Quek SC. The many estimates of the COVID-19 case fatality rate. Lancet Infect Dis 2020;20(7):776-777. DOI: 10.1016/S1473-3099(20)30244-9.

20. Pellaud C, Grandmaison G, Pham Huu Thien HP, Hoa Phong PH, Baumberger M, Carrel G, et al. Characteristics, comorbidities, 30-day outcome and in-hospital mortality of patients hospitalised with COVID-19 in a Swiss area - a retrospective cohort study. Swiss Med Wkly 2020;150:w20314. DOI: 10.4414/smw.2020.20314.

21. United Nations, Department of Economic and Social Affairs. World population ageing 2019 highlights; 2019. Available from: https:// www.un.org/en/development/desa/population/publications/pdf/ ageing/WorldPopulationAgeing2019-Highlights.pdf.

22. Singh AK, Gillies $C L$, Singh R, Singh A, Chudasama $Y$, Coles $B$, et al. Prevalence of co-morbidities and their association with mortality in patients with COVID-19: a systematic review and meta-analysis Diabetes Obes Metab 2020;22(10):1915-1924. DOI: 10.1111/dom.14124.

23. Singh AK, Gupta R, Misra A. Comorbidities in COVID-19: outcomes in hypertensive cohort and controversies with renin angiotensin system blockers. Diabetes Metab Syndr 2020;14(4):283-287. DOI: 10.1016/ j.dsx.2020.03.016.

24. Sun YJ, Feng YJ, Chen J, Li B, Luo ZC, Wang PX. Clinical features of fatalities in patients with COVID-19. Disaster Med Public Health Prep 2020;1-3. DOI: 10.1017/dmp.2020.235.

25. Liu S, Yao N, Qiu Y, He C. Predictive performance of SOFA and qSOFA for in-hospital mortality in severe novel coronavirus disease. Am J Emerg Med 2020;38(10):2074-2080. DOI: 10.1016/j.ajem.2020.07.019.

26. Zhou F, Yu T, Du R, Fan G, Liu Y, Liu Z, et al. Clinical course and risk factors for mortality of adult in patients with COVID-19 in Wuhan, China: a retrospective cohort study. Lancet 2020;395(10229):10541062. DOI: 10.1016/S0140-6736(20)30566-3.

27. Martinez AC, Dewaswala N, Tuarez FR, Pino J, Chait R, Chen K, et al. Validation of SOFA score in critically ill patients with COVID-19. Chest 2020;158(4):A613. DOI: 10.1016/j.chest.2020.08.577.

28. Chen Y, Li T, Ye Y, Chen Y, Pan J. Impact of fundamental diseases on patients with COVID-19. Disaster Med Public Health Prep 2020:1-6. DOI: 10.1017/dmp.2020.139.

29. Ahmed AR, Ebad CA, Stoneman S, Satti MM, Conlon PJ. Kidney injury in COVID-19. World J Nephrol 2020;9(2):18. DOI: 10.5527/wjn.v9.i2.18.

30. Keeley P, Buchanan D, Carolan C, Pivodic L, Tavabie S, Noble S. Symptom burden and clinical profile of COVID-19 deaths: a rapid systematic review and evidence summary. BMJ Support Palliat Care 2020;10(4):381-384. DOI: 10.1136/bmjspcare-2020-002368.

31. Chang TH, Wu JL, Chang LY. Clinical characteristics and diagnostic challenges of pediatric COVID-19: a systematic review and metaanalysis. J Formos Med Assoc 2020;119(5):982-989. DOI: 10.1016/ j.jma.2020.04.007.

32. Patel NA. Pediatric COVID-19: systematic review of the literature. Am J Otolaryngol 2020;41(5):102573. DOI: 10.1016/j.amjoto.2020.102573.

33. Jeng MJ.Coronavirus disease 2019 in children: current status.JChin Med Assoc 2020;83(6):527-533. DOI: 10.1097/JCMA.0000000000000323. 